\title{
POST-OPERATIVE SECURITY IN CATARACT CASES
}

\author{
BY
}

\author{
T. G. WYNNE PARRY \\ BANGOR, N. WALES
}

THE simple procedure described below, was devised to meet the case of an old lady of over eighty, whose mental and physical "wanderings" during her first night in hospital-where she had come for an extraction of one of her bilateral cataracts-gave rise to much foreboding as to her post-operative nursing.

The usual methods of trying to secure sound protection for the eye and the wound, were all thought of and discarded for various reasons : corneo-scleral suturing meant, later removal of the suture, and did not seem to give the maximum security which one was aiming at; the van Lint flap had always appeared to me to give a line of tension across the middle of the cornea along the edge of the flap, and it seemed difficult with this method to get pressure to bear evenly on the wound, cornea, and sclera.

Finally, it was decided to try a complete conjunctival flap, i.e., involving the whole circumference of the cornea. Accordingly, after the usual surface anaesthesia combined with retrobulbar injection anaesthesia and 7 th nerve block over the mapdible, a snip was made with scissors in the conjunctiva at the corneo-scleral margin to the outer side, a Weber's knife was inserted, and with the conjunctiva held taut with forceps at intervals all the way round, the conjunctiva was cut round the cornea. It was then undermined freely, and with $4 / 0$ catgut, a purse string suture was run round the conjunctival edge-the two ends being at 5 and 7 o'clock. The conjunctival flap was now gently retracted away and a simple corneo-scleral section was made and, after iridectomy, the lens was extracted in capsule. The iris pillars were stroked back, and then, with the conjunctival margin helped over the wound with a couple of iris repositors, the purse string suture was drawn tight and tied gently but firmly. The whole cornea was thus covered with conjunctiva, and the general appearance gave one a most unusual feeling of security. The one eye only was bandaged, and the patient walked back to bed, and was ambulatory from the first day:

The suture started giving on the 3rd day, and the whole cornea was clear on the 14 th - an unusually long period compared with succeeding cases. The whole convalescence was uneventful, the only treatment being my usual one of gtt. penicillin in flavazole,

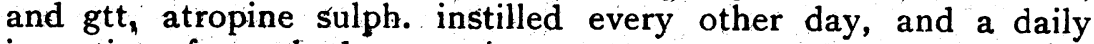
inunction of ung. hydrarg.

Following this case, I carried out the same procedure in eleven 
more cases. Out of this total of twelve cases done in the last 4 to 5 months-eight were intracapsular extractions, and four extracapsular. In one of the intracapsular cases there was some vitreous loss after the lens was extracted, but in neither this case nor any of the others were there any unusual symptoms, and the end results were excellent.

In the last eleven cases before the suture was finally drawn tight, gtt. penicillin and gtt. atropine were instilled into the mouth of "the bag." A small point which led to a little trouble with fixation of the eye in the first case, was that a small tag of conjunctiva should be left on the corneal margin at the point the operator usually prefers to place his fixation forceps-otherwise he finds it difficult to grip the eye without doing so on one of the recti muscles.

The suture was usually found to give about the 4th or 5th day, and the conjunctiva had retracted to the corneal margin by the 6th or 7th day. In only one case-for ultra-aesthetic reasons-was it necessary to help the conjunctiva back into place at one point on the 10 th day.

The method is admittedly more tedious than the usual ones in vogue, but the feeling of complete security is very real. The purse string suture is easy to draw tightly and snugly, and the pressure over the whole cornea and wound is even and firm. The physiological conditions for wound healing are therefore ideal inasmuch as it is covered, supported, warm and sheltered from infection.

The fact that the patients can be ambulatory with safety after the first twenty-four hours is a marked advantage in these days of depleted nursing staffs, and any post-operative complications which may arise-with the exception of infection-are in eftect dealt with before they happen.

I very much doubt if this procedure is original since nearly everything has been tried sometime, but I have not seen any reference to it in the literature available to me, and it is presented in the hope that it may be found to be a useful addition to the usual methods.

\section{THE POWER OR "POWERS" OF" A LENS}

BY

Joseph I. Pascal, M.D.

NEW YORK

IF a doctor at an Ophthalmological Board examination were asked, "What is the power of the crystalline lens?", he might well ask which of the different "powers" of the lens was wanted. In situ the lens may be said to have three powers, based on actual focal 